\title{
PENGARUH KEBUDAYAAN ASING DALAM PEMBENTUKAN RAGAM HIAS PELAMINAN NAREH PARIAMAN
}

\author{
Nofi Rahmanita *)
}

\begin{abstract}
The Handicraft of embroidery "palaminan" in Nareh Pariaman is an old culture product which is used for social purposes. As the time goes, now, the "palaminan" is not only used by the king or noblesse. Right now, it has been used in mostly wedding parties of Minangkabau tradition. It is used as the seat of the bride groom and bride who are called king and queen for a day. Regarding this theme, when we see the several various of palaminan, it looks like been influenced by the Chinese and Hindi/Gujarat Custom. Such as phoenix 9(bird) and lion decorated at the "palaminan", or for the Gujarat custom, there are embroidery with mirrors that decorate the palaminan. The mirror embroidered for the people of Nareh Pariaman has the meaning "suluah bendang" in the village.

The art of embroidery palaminan Nareh Pariaman has many structures which are connected to each other. They can not be separated in each use. The structures are decorated by the many kinds of Minangkabau decoration. Most of the decorating comes from application of the Minangkabau's philosophy known as "alam takambang Jadi Guru". The philosophy has symbolic meaning that contains some lessons about managing humans life, especially for people of Nareh Pariaman.
\end{abstract}

Keywords: beyond culture, motif, pelaminan

\section{Pendahuluan}

\begin{abstract}
Palaminan dalam pengertian luas dan umum adalah seperangkat (satu unit kesatuan) hiasan dalam sebuah rumah gadang milik suatu kaum, dalam serangkaian upacara perkawinan (Thaib, 2009:7). Dalam Ensiklopedi Minangkabau dijelaskan bahwa:
\end{abstract}

Kata palaminan berasal dari kata lamin, berarti jenis dan kemudian menjadi kelamin. Palaminan adalah tempat sepasang pengantin duduk bersanding dalam sebuah acara perkawinan. Pembeda jenis antara lakilaki dan perempuan. Pengertian palaminan kemudian menjadi terbatas, yaitu sebuah tempat yang dihiasi sedemikian rupa untuk pengantin bersanding berdua (Asnan, 2003:309).

Pemakaian palaminan dalam budaya Minangkabau, dibedakan atas dua macam, yaitu palaminan untuk pengangkatan penghulu dan palaminan untuk anak daro. Namun dari kedua palaminan tersebut tidak terdapat perbedaan yang mencolok, baik dari segi struktur bentuk, warna, maupun ragam hias yang menghiasi palaminan. Perbedaan dari kedua palaminan tersebut adalah adanya pemakaian payung kuning dan tabia dindiang yang berwarna-warni dalam pengangkatan

\footnotetext{
*Nofi Rahmanita (ukeramik@yahoo.com), Staf Pengajar Program Studi Kriya Seni, Jurusan Kriya, Fakultas Seni Rupa, Institut Seni Indonesia Padang Panjang
} 
penghulu, sementara pada palaminan anak daro tidak terdapat unsur palaminan tersebut (Wawancara dengan Nurcani tanggal 6 Maret 2010 di Sentra Pelaminan One).

Menurut sumber sastra, palaminan merupakan mahar dari seorang Raja Cina untuk meminang Bundo Kanduang (Abdullah dalam Verayanti, 2003:29). Sementara kiriman mahar masih dalam perjalanan ke Sumatera Barat, Raja Cina meninggal dunia. Untuk mengenangnya, digunakanlah palaminan pada setiap upacara adat di Minangkabau (Aswar, 1999:42). Jadi, jika dilihat secara kasat mata, palaminan Minangkabau mendapat pengaruh dari budaya Cina. Selain terpengaruh budaya Cina juga terdapat unsur budaya Gujarat (Anthonyswan, 2007:89).

Palaminan sebagai tempat bersanding kedua pengantin menyerupai singgasana raja, yang terbentuk dari susunan struktur bentuk seni rupa dan dihiasi dengan ragam hias (Djelantik, 2004:18). Susunan dari struktur bentuk palaminan dan ragam hias yang menghiasi palaminan, bukan hanya sekedar untuk memenuhi rasa keindahan semata, tapi di balik keindahan palaminan tersimpan makna simbolik yang dalam (Sundari, 2004:32). Ragam hias Minangkabau bertolak dari falsafah kehidupan, yaitu: alam takambang jadi guru, yang artinya segala sesuatu yang ada pada alam dan lingkungannya dijadikan sebagai sumber adat.

Ragam hias Minangkabau dalam pembentukannya sudah tidak menyerupai bentuk asli dari ornamen yang diciptakan. Bentuk yang ada pada alam digubah menjadi ragam hias. Secara visual, bentuk dan ragam hias yang ditampilkan telah dikembangkan dengan berbagai macam kreasi dan modernisasi dalam penataan, namun tetap pada batas yang harus ditaati. Adapun ragam hias Minangkabau yang diterapkan pada palaminan antara lain: puti takuruang, ula gerang, itiak pulang patang, pucuak rabuang, ombak-ombak, biku-biku, ati-ati basandiang, saluak laka, dan lain-lain, yang kesemuanya sejalan dengan pandangan hidup masyarakat Minangkabau. Selain terdapat ragam hias Minangkabau juga terdapat motif hias Cina yang tidak mempunyai arti bagi masyarakat Minangkabau, misalnya burung Phoenix, naga, singa, bunga Krisan, dan bunga Peony (Aswar, 1999:2).

Palaminan merupakan suatu warisan budaya yang terus bertahan sampai sekarang, dan memiliki suatu kesatuan struktur bentuk yang organis. Aspek estetik dari palaminan seperti motif, warna, teknik dan unsur pembentuk merupakan hal yang menarik untuk dikaji.

\section{Pembahasan}

Di Pariaman terdapat dua buah pelabuhan sebagai tempat transaksi jalur perdagangan dengan daerah luar, seperti Cina, Gujarat, dan Aceh. Hubungan dagang saat itu sifatnya pribadi, dalam arti mereka saling mengenal secara dekat dan terjadi komunikasi budaya, tanpa disadari mengakibatkan terjadinya penyerapan unsurunsur budaya (Mansoer, 1970:42). Dengan adanya komunikasi antarbudaya tersebut, secara tidak sengaja terjadi suatu proses akulturasi dalam kebudayaan masyarakat Minangkabau pada umumnya, masyarakat Nareh Pariaman pada khususnya, sehingga berdampak pada pembentukan ragam hias sulam Palaminan Nareh Pariaman.

\section{Akulturasi Budaya Masyarakat Pariaman}

Masyarakat Minangkabau pada umumnya, masyarakat Nareh Pariaman pada khususnya sangat terbuka terhadap 
perubahan dan adanya kemampuan masyarakat Minangkabau, khususnya masyarakat Nareh saat itu untuk memadukan kebudayaan asli dengan kebudayaan luar, dalam hal ini kebudayaan Cina dan Gujarat. Sjafri Sairin menjelaskan bahwa sifat keterbukaan orang Minangkabau dalam memandang perubahan adalah sebagai peristiwa dan wajar-wajar saja. Orang Minangkabau dengan mudah dapat menerima ide dan benda material yang berasal dari luar budayanya, selama hal itu tidak menganggu kebudayaan yang telah mapan (2002:184).

Teori kebudayaan menyebutkan bahwa perkembangan kebudayaan lebih banyak dipengaruhi oleh faktor dari luar, yaitu pengaruh kebudayaan lain yang mempengaruhi kebudayaan lama (Soedarso, 2006:7). Lebih lanjut Soedarso Sp, menjelaskan bahwa:

Akulturasi adalah suatu keadaan yang dihasilkan oleh karena adanya pertemuan yang serius dan terusmenerus antara sekelompok manusia dengan kelompok lain yang memiliki kebudayaan yang berbeda dan menimbulkan perubahan pada pola kebudayaan aslinya baik di salah satu sisi atau kedua kelompok yang bertemu (2006:73-74).

Lebih lanjut Agus Sachari juga menyatakan bahwa proses akulturasi merupakan keseragaman (homogeneity), seperti nilai baru yang tercerna akibat keserupaan tingkat dan corak budayanya. Kemudian syarat fungsi, seperti nilai baru yang diserap hanya sebagai suatu manfaat yang tidak penting atau hanya sekadar tampilan, maka proses akulturasi berlangsung dengan cepat. Dengan demikian, suatu nilai yang tepat fungsi dan bermanfaat bagi pengembangan kebudayaan akan memiliki daya tahan yang lama (2002:73). Selain itu proses akulturasi adalah unsur diterimanya kebudayaan luar yang diolah ke dalam kebudayaan sendiri tanpa menyebabkan hilangnya kepribadian kebudayaan asal (Koenjaraningrat dalam Agus Sachari, 2002:73).

Palaminan memegang peranan penting dalam setiap upacara adat di Minangkabau. Palaminan termasuk seni dekorasi interior Minangkabau yang banyak dipengaruhi oleh budaya Cina. Seperti telah dijelaskan sebelumnya bahwa Cina datang ke Pariaman sekitar tahun 1630-an. Pada umumnya, mereka adalah saudagar Cina yang berasal dari Banten. Mereka datang ke Pariaman untuk mencari lada dan bekerja sebagai agen dari pialang Cina di Banten. Jumlah kunjungan saudagar Cina selalu meningkat hingga pertengahan abad ke-17 (Asnan, 203:216). Fakta lain yang membuktikan bahwa ada penyerapan budaya Cina, seperti yang dikutip dalam Aswar bahwa:

Seorang Raja Cina pernah meminang bundo kanduang dengan mengirim seperangkat palaminan sebagai tanda ikatan. Tetapi sementara kiriman itu masih dalam perjalanan ke Sumatera Barat, ia meninggal dunia di negerinya. Untuk mengenangnya, digunakanlah palaminan pada setiap upacara adat di Minangkabau (1999:42).

Dinyatakan Aswar, H. DJ. Datuk Bandaro Lubuk Sati memperkuat keterangan di atas bahwa bundo kanduang pernah dilamar 7 kali dengan orang yang berbeda, masing-masing membawa hadiah sebagai ikatan. Salah satunya adalah bawaan Raja Cina yaitu seperangkat palaminan (1999:43).

Unsur palaminan yang mendapat resapan dari budaya Gujarat dapat dilihat 
pada sulaman kaca yang ada pada elemen palaminan. Sulaman kaca pada palaminan dijahitkan di atas dasar kain dan diterapkan pada unsur palaminan, seperti banta gadang, tirai tabia dindiang, dan dulamak. Menurut One Nurcani, sulaman kaco yang terdapat pada palaminan merupakan cerminan kedudukan ninik mamak sebagai suluah bendang (penerang) dalam nagari (Wawancara dengan Nurcani tanggal 6 Maret 2010 di pelaminan One). Sulaman kaco dapat dilihat pada banta gadang, tabia dindiang, tirai langik, dan dulamak.

\section{Pengaruh Budaya Asing dalam Pembentukan Ragam Hias Palaminan}

Pariaman yang terletak di pinggir pantai, sehingga mudah dikunjungi pelaut dari berbagai negeri, menyebabkan mudah pula berhubungan dengan daerah lain. Sebuah teori dari Westenenck mengatakan bahwa dahulu di Pariaman mempunyai pelabuhan yang terletak di sebuah teluk kecil, sedikit ke arah Timur kota Pariaman sekarang. Pelabuhan ini sudah disinggahi oleh kapal dari Tiongkok. la juga mengatakan bahwa kira-kira 20 tahun yang lalu di kampung yang bernama Taratak terdapat banyak benda yang terbuat dari tanah asal Cina, misalnya porselen, mangkok, dan lain-lain dengan tulisan Cina. Porselen tersebut sebagian berasal dari kekayaan yang tersimpan dalam kapal yang kebetulan tertambat di pelabuhan milik dari Kaisar Tiongkok yang pada saat itu bertunangan dengan Putri Bungo Tanjung dari Minangkabau. Ketika Kaisar Cina cuti ke negerinya, ia meninggal dunia (Amran, 1981:239).

Penjelasan Westenenck di atas sesuai dengan penjelasan yang dikutip dalam Aswar yang menyatakan bahwa ada seorang raja
Cina pernah meminang bundo kanduang dengan mengirim seperangkat palaminan sebagai tanda ikatan. Tetapi sementara kiriman itu masih dalam perjalanan ke Sumatera Barat, ia meninggal dunia di negerinya.

Catatan tertua lain mengenai Pariaman ditemukan oleh Tome Pires pada abad ke-16. la mencatat bahwa telah ada lalu lintas dagang antara India dengan beberapa kota pelabuhan, seperti Pariaman, Tiku, dan Barus, di sepanjang pantai Barat Sumatera. la juga mengatakan bahwa dua-tiga kapal dari Gujarat mengunjungi pelabuhan Pariaman setiap tahunnya, membawa kain untuk penduduk asli yang dibarter dengan emas, kayu gaharu, kapur barus, sutera, lilin, dan madu. Pires juga menyebutkan bahwa Pariaman melakukan perdagangan kuda yang dibawa dari daerah Batak secara besarbesaran dengan daerah Sunda (Suryadi, 2002:131-132).

Dari penjelasan sejarah di atas dapat ditarik kesimpulan bahwa dengan datangnya bangsa luar, yaitu Cina dan Gujarat ke Pariaman untuk berdagang, tanpa disadari terjadi saling ambil-mengambil unsur-unsur kebudayaan masing-masing (Mansoer, 1970:42). Pengaruh tersebut bisa kita lihat pada salah satu produk budaya Minangkabau, khususnya Nareh Pariaman, yaitu palaminan. Unsur-unsur palaminan mendapat pengaruh, misalnya munculnya ragam hias Cina, warnawarna cerah, serta sulaman kaca dari Gujarat.

Mengenai kesenian Gujarat yang masuk ke Minangakabau, khususnya Nareh Pariaman, Anthonyswan menjelaskan bahwa seni dekorasi berupa sulaman kaca berasal dari seni sulaman kaca Gujarat. Diketahui kesenian tersebut masuk ke Minangkabau setelah kebudayaan Parsi berkembang, artinya pengaruh Islam sudah masuk di Gujarat. Orang-orang dari Gujarat yang datang 
berniaga ke pantai Tiku Pariaman membawa serta budaya tersebut ke Sumatera (2007:89).

\section{Ragam Hias Cina yang Mendukung Pembentukan Palaminan}

Daerah pesisir atau pinggir pantai, seperti pantai Barat Sumatera (Pariaman, Tiku), pesisir Utara dari pulau Jawa, sejak dahulu sudah mendapat pengaruh kuat dari Tiongkok. Hal ini antara lain dapat dilihat pada sulam palaminan dan kain batik. Ragam hiasnya sebagian besar bercorak Tiongkok. Begitu juga di daerah Bali, banyak terdapat pengaruh Tiongkok. Hal ini bisa kita lihat pada kain prada, yaitu kain yang perhiasannya dibuat dengan prada. Ragam hiasnya terdapat corak Tiongkok, yaitu meander dan burung Phoenix (Hoop, 1949: 201-204).
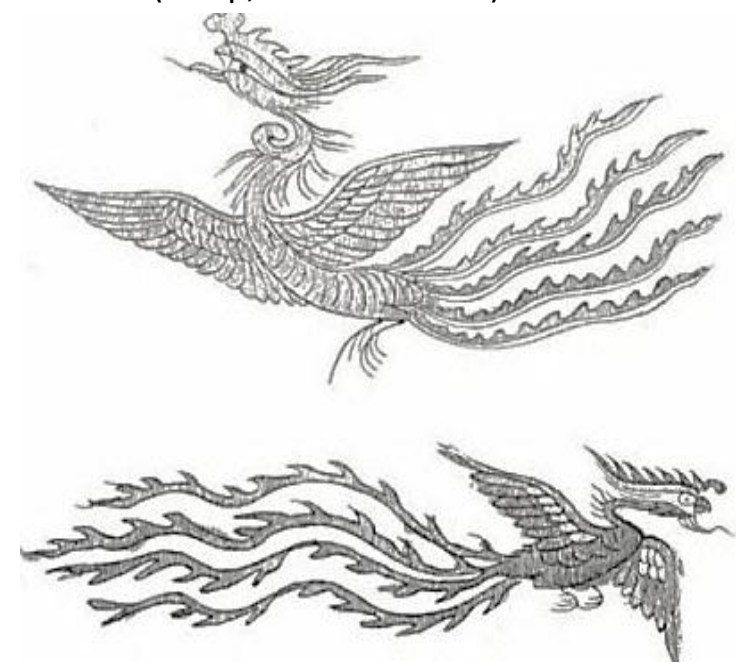

Gambar 1.

Motif Burung Phoenix

(Sumber: Van Der Hoop, 1949: 2001)

Burung Phoenix terkenal di Cina sebagai burung mitos. Keramik yang berasal dari Cina banyak terdapat di Nusantara dihiasi dengan burung Phoenix, dan kemudian motif ini menyebar di daerah yang melakukan kontak dengan Cina. Bentuk burung phoenix mirip burung merak, tetapi ciri yang menonjol ialah pada ekornya yang panjang bergelombang tanpa bulatan. Motif burung Phoenix mengandung makna sebagai burung surga dan sebagai lambang dunia atas atau langit.

Setelah masuk ke Minangkabau khususnya Nareh, bentuk burung phoenix telah berubah bentuk sesuai imajinasi pengubahnya. Sebuah contoh dapat kita lihat pada sulam palaminan, burung Phoenix telah mengalami pengubahan bentuk.

Pada gambar 1 burung Phoenix Cina belum mendapat gubahan dari perajin. Salah satu ciri khas yang dapat dilihat adalah ekornya yang panjang bergelombang tanpa bulatan di ujung ekor.
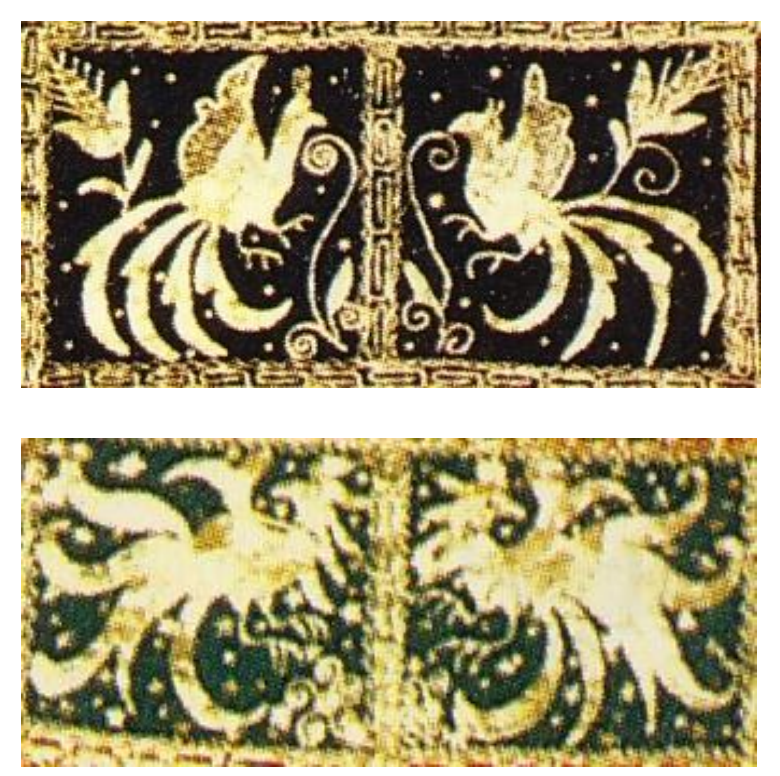

Gambar 2.

Motif Burung Bersulam Benang Emas yang Terdapat pada Banta Gadang

(Answar, 1999: 51)

Sementara, motif burung pada gambar 2 merupakan burung Phoenix yang telah mengalami perubahan oleh perajin sulam palaminan Nareh. Motif burung Phoenix yang telah diubah, dijahit dengan sulam benang emas yang berfungsi sebagai unsur estetik dan tidak memiliki makna bagi masyarakat Nareh Pariaman. 


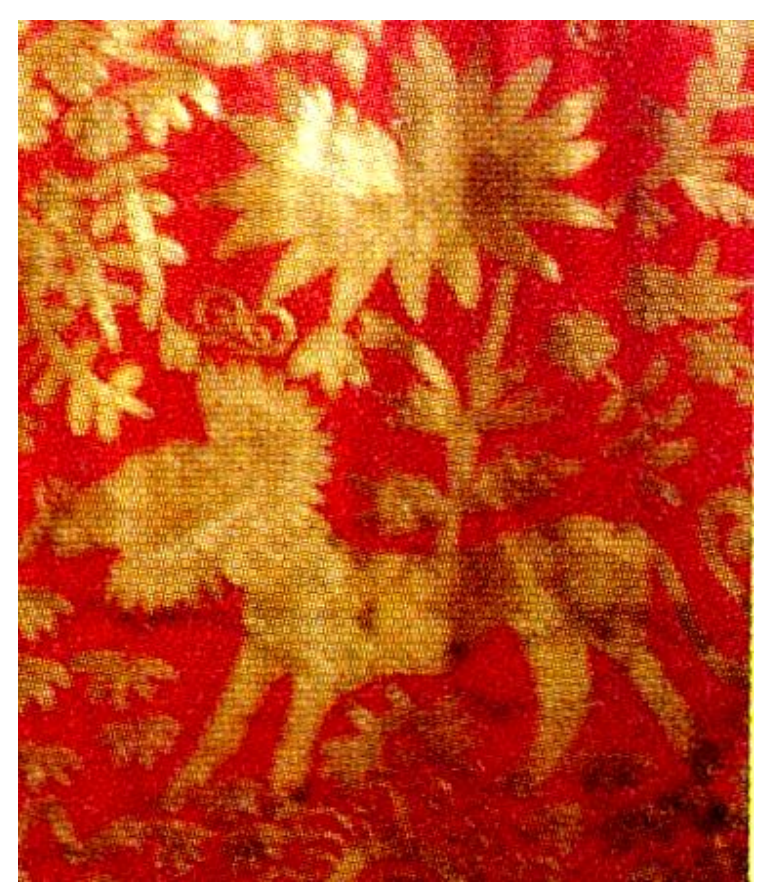

Gambar 3.

Motif Singa Bersulam Benang Emas

(Foto: Nofi Rahmanita, 20 Juni 2010)

Motif singa bersulam benang emas pada gambar 3 terdapat pada tirai tabia dindiang yang dijahit di atas dasar kain beludru. Motif tersebut berfungsi sebagai unsur estetik dan tidak memiliki makna bagi masyarakat Nareh Pariaman.

\section{Penutup}

Pariaman merupakan salah satu kota tertua di Pesisir Barat Minangkabau. Kota Pariaman juga merupakan bandar dagang yang ramai dikunjungi oleh para pedagang dari luar daerah. Sebagai bandar dagang, terjadi interaksi perdagangan antara masyarakat Nareh Pariaman dengan saudagar Cina dan Gujarat, sehingga terjadi komunikasi budaya dan tanpa disadari mengakibatkan terjadinya penyerapan unsur-unsur budaya. Adanya komunikasi antarbudaya tersebut, maka secara tidak sengaja terjadi suatu proses akulturasi dalam kebudayaan masyarakat Minangkabau pada umumnya, masyarakat
Nareh Pariaman pada khususnya. Pengaruh tersebut dapat kita lihat pada salah satu produk budaya Minangkabau, khususnya Nareh pariaman, yaitu palaminan. Unsurunsur yang ada pada palaminan terdapat ragam hias Cina dengan warnanya yang cerah, sedangkan seni sulam kaca berasal dari seni sulam kaca Gujarat. Ragam hias palaminan Nareh Pariaman mengandung makna nilai estetik dan simbolik melalui terjalinnya interaksi sosial dan budaya yang terjadi di daerah Nareh Pariaman.

\section{Daftar Pustaka}

Amran, Rusli.1981. Sumatera Barat hingga Plakat Panjang. Jakarta: Sinar Harapan.

Anthonyswan. 2007. Latar Sejarah Indo Jalito Bundo Kanduang di Minangkabau. Batusangkar: CV. Sarana Wisata Enterprise.

Asnan, Gusti. 2003. Kamus Sejarah Minangkabau. Padang: Pusat Pengkajian Islam dan Minangkabau.

Aswar, Sativa Sutan. 1999. Antakesuma Suji dalam Adat Minangkabau. Jakarta: Djambatan.

Djelantik, A. A. M. 2004. Estetika Sebuah Pengantar. Bandung: Masyarakat Seni Pertunjukan Indonesia.

Hoop, Van Der. 1949. Indonesche Siermotiven. Koninklijk Bataviaasch Genootschap Van Kunsten en Wetenschappen,.

Mansoer, dkk.1970. Sejarah Minangkabau. Jakarta: Bharata. 
Sachari, Agus. 2002. Estetika Makna, Simbol, dan Daya. Bandung: ITB Bandung.

Sairin, Sjafri. 2002. Perubahan Sosial Masyarakat Indonesia: Perspektif Antropologi. Yogyakarta: Pustaka Pelajar.

Soedarso SP. 2006. Trilogi Seni Penciptaan Eksistensi dan Kegunaan Seni. Yogyakarta: ISI Yogyakarta.

Sundari, Sri. 2004. "Keberadaan Pelaminan sebagai Sarana Ritual dalam Adat Perkawinan di Kotamadya Padang". Padangpanjang: STSI Padangpanjang.

Suryadi. 2002. Syair Sunur Teks dan Konteks "Otobiografi" Seorang Ulama Minangkabau Abad Ke-19. Pusat Pengkaian Islam dan Minangkabau.

Tahib, Puti Reno Raudha. 2009. Pelaminan Minangkabau. Sumatera Barat: Bundo Kanduang.

Verayanti, et. al. 2003. Partisipasi Politik Perempuan Minang dalam Sistem Masyarakat Matrilinial. Padang: LP2M. 


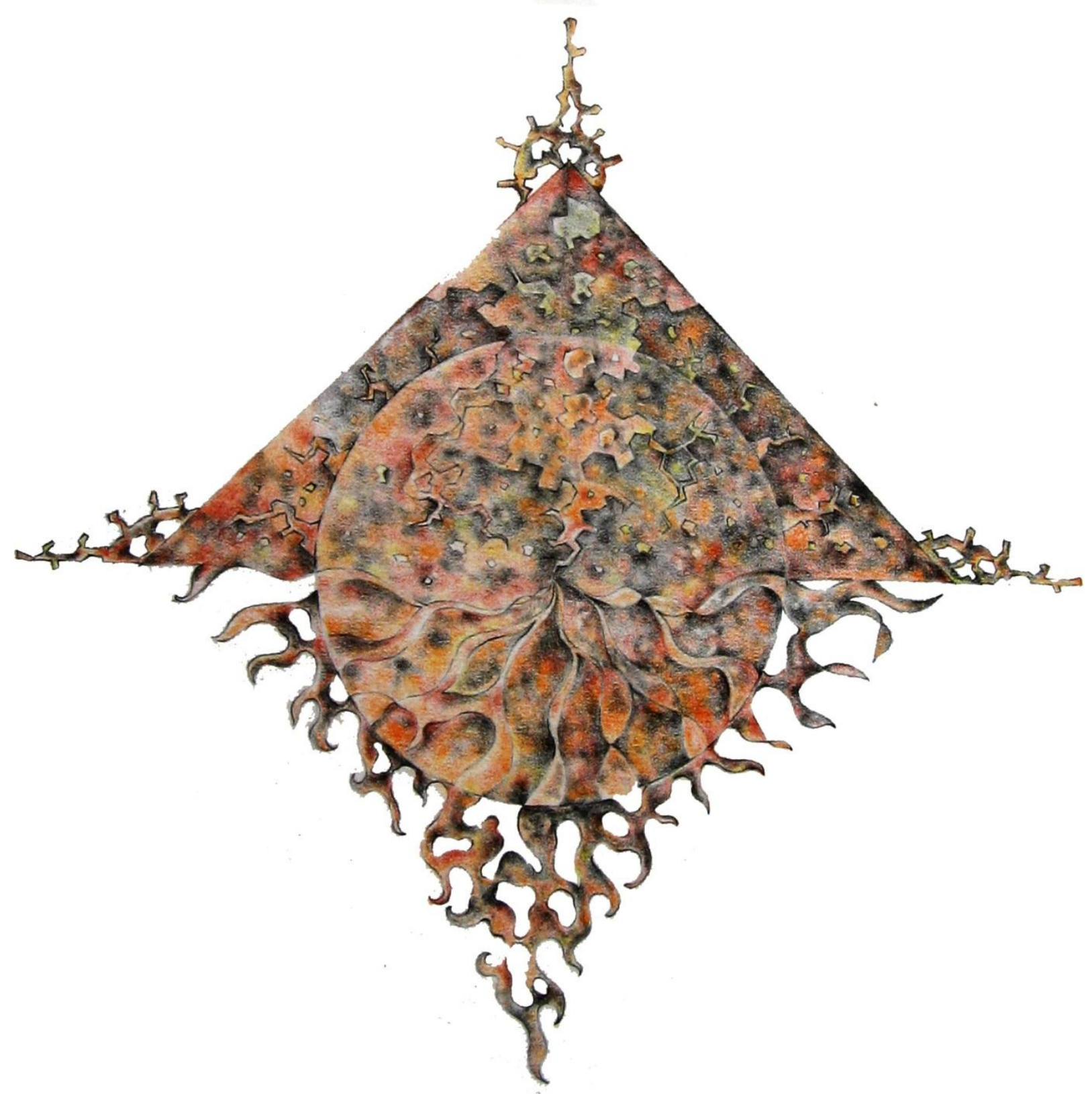

Budi Hartono

Balance

Tembaga dan cor kuningan

$150 \mathrm{~cm} \mathrm{X} 150 \mathrm{~cm}$

2012 